\title{
Efficacy of Curosurf in a rat model of acute respiratory distress syndrome
}

\author{
H.P.M. van Helden*, W.C. Kuijpers*, P.E.J. Langerwerf*, R.C.J. Langen*, \\ H.P. Haagsman**, P.L.B. Bruijnzeel*
}

Efficacy of Curosurf in a rat model of acute respiratory distress syndrome. H.P.M. van Helden, W.C. Kuijpers, P.E.J. Langerwerf, R.C.J. Langen, H.P. Haagsman, P.L.B. Bruijnzeel. COERS Journals Ltd 1998.

ABSTRACT: Curosurf, a natural lung surfactant, is considered a potential candidate for improving the treatment of acute respiratory distress syndrome (ARDS).

To investigate this in a rat model of early-stage ARDS, Curosurf $(62.5,125$ or 250 mg.kg-1) was administered by intratracheal bolus at 10 or $24 \mathrm{~h}$ following an intratracheal lipopolysaccharide (LPS; $1.6 \mathrm{mg} \cdot \mathrm{kg}^{-1}$ ) challenge. Survival, respiratory frequency $(f \mathrm{R})$, lung wet weight $(\mathrm{LWW})$, total protein and cell differentiation in bronchoalveolar lavage fluid (BALF) were assessed.

Curosurf treatment at $10 \mathrm{~h}$ after LPS challenge resulted in $100 \%$ survival at both 62.5 and $125 \mathrm{mg} \cdot \mathrm{kg}^{-1}$; at a dose of $250 \mathrm{mg} \cdot \mathrm{kg}^{-1}$ administered at $10 \mathrm{~h}$ after LPS, 1 out of 6 animals died. At a dose of $125 \mathrm{mg} \cdot \mathrm{kg}^{-1}$ Curosurf administered at $24 \mathrm{~h}$ after LPS, 1 out of 6 animals died. In contrast, only $35 \%$ of animals survived when not treated with Curosurf. Curosurf treatment resulted in an improved $f R$ and in a significantly decreased LWW, total protein and number of polymorphonuclear cells in BALF.

In conclusion, Curosurf treatment improved respiratory frequency and decreas- ed mortality, pulmonary oedema and inflammation. As the decreased mortality was observed in spontaneously breathing nonoxygenated animals, the results cannot be extrapolated to human artificially ventilated acute respiratory distress syndrome patients with the expectation of a decreased mortality. The results suggest, however, that Curosurf may be an important therapeutic measure in early-stage acute respiratory distress syndrome.

Eur Respir J 1998; 12: 533-539.
*TNO Prins Maurits Laboratory, Research Group Pharmacology, Rijswijk, The Netherlands. **Laboratory of Veterinary Biochemistry, Utrecht University, Utrecht, The Netherlands

Correspondence: H.P.M. van Helden

TNO Prins Maurits Laboratory

Research Group Pharmacology

P.O. Box 45

2280 AA Rijswijk

The Netherlands

Fax: 31152843963

Keywords: Acute respiratory distress syndrome

animal model

Curosurf

lung surfactant

Received: October 281997

Accepted after revision May 121998
Since its first description by AsHBAUGh et al. [1] mortality due to acute respiratory distress syndrome (ARDS), has decreased to around $40 \%[2,3]$, suggesting some progress in therapy. Pharmacological interventions, however, such as treatment with prostaglandin E1 (PGE1) and corticosteroids or conventional ventilatory interventions and extracorporal membrane oxygenation (ECMO) have not been shown to improve survival of these patients.

Therefore there is a need for alternative therapeutic interventions. One of these seems to be the lung surfactant system. Alterations in the surfactant system are proposed to contribute significantly to the pathophysiology of ARDS [4]. Changes in the surfactant system composition and function $[4,5]$ have been observed in bronchoalveolar lavage fluid (BALF) of ARDS patients. Moreover, there are a few reports on beneficial effects of surfactant treatment in ARDS patients [6, 7, 8] (for review see [9]).

An important role for surfactant in lung protection could also be illustrated in animal models deficient in surfactant; exogenous surfactant instillation dramatically improved blood gases and lung mechanics [10,11]. Therefore, it seems rational to administer exogenous surfactant to ARDS patients. However, this therapeutic approach is hampered by the costs; natural surfactants are very expensive. For this reason it is expected that more synthetic sur- factants will be developed. These synthetic products include formulations that are relatively resistant to inhibition, have significant anti-inflammatory effects, and are promising in animal models of acute lung injury as in ARDS [12]. To date, natural surfactants are still more effective than synthetic ones.

Three natural surfactants, Curosurf, Survanta and Alveofact, seem to have the potency to improve the therapeutic intervention in ARDS considerably. During a recent multicentre trial [13], Survanta was administered via direct intratracheal (IT) instillation. The ARDS subjects were treat-ed with either four or eight doses of Survanta (100 $\left.\mathrm{mg} \cdot \mathrm{kg}^{-1}\right)$. This treatment produced a significant decrease in mort-ality. The strongest improvement in pulmonary gas ex-change occurred during the first four surfactant doses (degree of change in the arterial oxygen tension $\left(\mathrm{Pa}, \mathrm{O}_{2}\right) /$ inspiratory oxygen fraction $\left(F \mathrm{I}, \mathrm{O}_{2}\right)$ ratio). In contrast, GREGORY et al. [14] reported no significant $(\mathrm{p}=0.075)$ decrease in overall mortality using Survanta. Alveofact was shown by WaLMRATH et al. [15] to improve oxygenation and gas exchange in 10 patients with ARDS.

Since Curosurf has proved to be effective in respiratory distress syndrome patients, we consider it a potential candidate to improve the treatment of ARDS and therefore investigated its therapeutic efficacy in our rat model of 
ARDS [16]. Briefly, ARDS is induced by IT aerosolization of the endotoxin, lipopolysaccharide (LPS) of Gramnegative bacteria. This results within $24 \mathrm{~h}$ in a syndrome comparable with that seen in patients suffering from ARDS. The observed lung injury includes an inflammatory density on chest radiographs, a severe hypoxaemia, a decline in lung compliance, and an enhanced level of positive end-expiratory pressure (PEEP). In addition, other typical features of human ARDS are present in our model: 1) increased microvascular permeability reflected by oedema, elevated levels of protein and lactic dehydrogenase (LDH), and increased numbers of polymorphonucleates (PMNs) in BALF; 2) high levels of tumour necrosis factor- $\alpha$ (TNF- $\alpha$ ) in BALF preceding the appearance of PMNs; 3) changes in breathing pattern and a gradual development of respiratory failure, resulting in 50\% mortality in the first week following LPS administration; and 4) surfactant protein (SP)-A levels in BALF doubled within $1 \mathrm{~h}$ after LPS administration, suggesting that this collection may play a role in the immediate inflammatory response. In this study we demonstrated that Curosurf had a therapeutic action in our rat model for ARDS.

\section{Materials and methods}

\section{Animals}

Male albino Wistar rats (180-200 g) obtained from Charles River (Sulzfeld, Germany) were used in this study. The animals were kept at a regular $12 \mathrm{~h}$ light /dark cycle, with a temperature of $22 \pm 2^{\circ} \mathrm{C}$. Food and water were given ad libitum.

\section{Procedure}

The efficacy of Curosurf was investigated in rats according to the following protocols: LPS (16 mg $\left.\cdot \mathrm{kg}^{-1} \mathrm{IT}\right)$ was administered at $t=0 \mathrm{~h}$ and Curosurf $(62.5,125$ or 250 $\mathrm{mg} \cdot \mathrm{kg}^{-1} \mathrm{IT}$ ) subsequently at $t=10$ or $24 \mathrm{~h}$.

Arguments for applying Curosurf at $10 \mathrm{~h}$ following LPS instillation were derived from previous experiments in which it was demonstrated that respiration already deteriorated at $10 \mathrm{~h}$ after LPS administration [16], although there was no need for artificial ventilation; at that time point lung wet weight (LWW) started to increase and the amount of SP-A assessed in BALF decreased. Furthermore, an increase of TNF- $\alpha$ in BALF preceded the infiltration of a large number of PMNs into the alveolar space. Summarizing, at $10 \mathrm{~h}$ following LPS administration there were clinical signs of ARDS although less severe than at $24 \mathrm{~h}$. Therefore greater therapeutic effects of Curosurf could be expected, when applied at $10 \mathrm{~h}$ than at $24 \mathrm{~h}$ after LPS administration.

In the first part of the study the following five groups of rats (180-200 g) were used in which the respiratory frequency $(f \mathrm{R})$ and survival were measured: 1) LPS (16 $\left.\left.\mathrm{mg} \cdot \mathrm{kg}^{-1}\right)(\mathrm{n}=6) ; 2\right) \mathrm{LPS}+$ Curosurf $\left(62.5 \mathrm{mg} \cdot \mathrm{kg}^{-1}\right)$ at $10 \mathrm{~h}$ after LPS $(\mathrm{n}=6) ; 3)$ LPS + Curosurf $\left(125 \mathrm{mg} \cdot \mathrm{kg}^{-1}\right)$ at $10 \mathrm{~h}$ after LPS (n=9); 4) LPS + Curosurf (250 mg.kg-1) at $10 \mathrm{~h}$ after LPS $(n=6)$; and 5$)$ vehicle $(n=6)$.

Subsequently, in separate experiments, similar groups of rats (except group 2) were committed to determine LWW/body weight (BW), total protein, total cell count and cell differentiation in BALF obtained $48 \mathrm{~h}$ after LPS. Therefore, these rats were sacrificed at $48 \mathrm{~h}$ after LPS administration.

In the second part of the study, high dosages of Curosurf were administered at $24 \mathrm{~h}$ after LPS instillation, a time point at which more lung injury could be expected. Therefore, the following three groups were used in which only $f \mathrm{R}$ was measured over $48 \mathrm{~h}$ after LPS administration: 1) LPS (16 mg. $\left.\left.\mathrm{kg}^{-1}\right)(\mathrm{n}=6) ; 2\right)$ LPS + Curosurf (125 mg $\left.\cdot \mathrm{kg}^{-1}\right)$ at $24 \mathrm{~h}$ afterLPS $(\mathrm{n}=6)$; and 3) LPS + Curosurf (250 $\left.\mathrm{mg} \cdot \mathrm{kg}^{-1}\right)$ at $24 \mathrm{~h}$ after LPS $(\mathrm{n}=6)$.

At $48 \mathrm{~h}$ after LPS administration these animals were sacrificed to determine $\mathrm{LWW} / \mathrm{BW}$, total protein, total cell count and cell differentiation in BALF obtained $48 \mathrm{~h}$ after LPS administration (and Curosurf treatment). In this part of the study survival was only investigated in a separate group of six animals treated with $125 \mathrm{mg} \cdot \mathrm{kg}^{-1}$ Curosurf at $24 \mathrm{~h}$ after LPS administration.

\section{Parameters to be measured}

Firstly the effect of Curosurf on $f \mathrm{R}$ and survival of "ARDS-rats" was investigated in a series of experiments. $f \mathrm{R}$ was measured online in a whole-body plethysmograph during $48 \mathrm{~h}$ following IT LPS aerosolization (see below). At the end of the experiment LWW/BW, reflecting the extent of oedema, was measured (see below); the number of different cell types was determined on the basis of cell counts and differential enumeration. The lungs of all animals were stored for histological examination afterwards.

\section{Administration of LPS and Curosurf}

Under brief halothane anaesthesia each rat was intubated with the aerosolizer guided by a fibreoptic light source. Phosphate-buffered saline (PBS vehicle) or LPS dissolved in PBS $(0.5 \mathrm{~mL})$ was aerosolized using a miniature nebulizer. The nebulizer consists of a $2 \mathrm{~mL}$ syringe in combination with a miniaturized nozzle mounted on the tip of a $5.5 \mathrm{~cm}$ stainless steel tube (diameter $1 \mathrm{~mm}$ ). This nebulizer allows dispersion and homogeneous distribution of a small volume $(0.5 \mathrm{~mL})$ of liquid into the lungs without the necessity of a large volume of air to act as a vehicle, which could damage the small rat lung [16]. The LPS solution was dispersed in the trachea just before the bifurcation. The size of most of the aerosol particles is in the range $10-70 \mu \mathrm{m}$ and the deposition fraction is nearly $100 \%$ since nebulization takes place in the trachea. A semiquantification of the density of the inflammatory process throughout the various lobes of the lungs, revealed a remarkable homogeneous distribution of PMNs $24 \mathrm{~h}$ after LPS administration [16]. After LPS administration, each animal was placed in a whole-body plethysmograph to measure $f \mathrm{R}$. The relatively high dose of LPS was needed to obtain a manifest clinical picture of ARDS within $24 \mathrm{~h}$. The "specific activity" of LPS, i.e. the percentage of the total amount of LPS which is biologically active, is being investigated.

Under short-duration halothane anaesthesia, Curosurf (12.5-50 mg per $0.15-0.6 \mathrm{~mL}$ per rat with body weight of $200 \mathrm{~g}$, corresponding to $62.5-250 \mathrm{mg} \cdot \mathrm{kg}^{-1}$ (see Procedure); a Curosurf vial contains $80 \mathrm{mg} \cdot \mathrm{mL}^{-1}$ ) was administered IT by bolus (just before the bifurcation of the trachea) by means of a $2 \mathrm{~mL}$ syringe with a special bent 
and blunt needle guided by a fibreoptic light source. The volume depended on the dose of surfactant needed.

\section{Assessment of $\mathrm{f} R$}

The equipment to measure the $f \mathrm{R}$ consisted of 1) a stand-alone computer with an analogue-to-digital (A/D) converter card type DAS8/PGA (Keithley Data Acquisition, Gorinchem, the Netherlands); and 2) a polyvinyl chloride (PVC)-tube with a diameter of $110 \mathrm{~cm}$ and a length of $300 \mathrm{~cm}$ containing the conscious animal. This tube could be closed at one side and connected to a plethysmograph on the opposite side. The signal produced by a constant air flow of $1 \mathrm{~L} \cdot \mathrm{min}^{-1}$ through the tube was considered as a baseline on which the breathing pattern of the animal was superimposed. A microprocessor (IBM, type 486, DX2 66 $\mathrm{MHz}$, Zoeterheer, the Netherlands) collected 512 data points (pressure differences) from the A/D converter in $3 \mathrm{~s}$ intervals. A timer started to run when the first data point was registered and terminated when 512 points had been collected. Each time the sinusoid respiratory signal crossed the abscissa, the programme registered a change from positive to negative and vice versa. In this way the $f \mathrm{R}$ could be calculated.

\section{Lung wet weight and bronchoalveolar lavage}

To determine LWW animals were sacrificed and the thorax was opened. The trachea was separated from thymus and oesophagus and cut just below the larynx. The lungs still connected to the heart were dissected and weighed. Then bronchoalveolar lavage was carried out using five subsequent volumes of $8 \mathrm{~mL}$ PBS buffer. These five volumes were pooled and the cells were pelleted by centrifugation. The supernatant $(40 \mathrm{~mL})$ was collected and stored at $-20^{\circ} \mathrm{C}$ and the cell pellet was resuspended in $1 \mathrm{~mL}$ PBS and used to perform differential cell counts (see below). Following lavage, the lung lobes were dissected from the trachea. To determine LWW, the total weight of heart and trachea were subtracted from the total weight of the trachea plus lungs and heart before performing the lavage. LWW is expressed as a percentage of whole BW (\% LWW/BW). Cellular constituents were determined by cytocentrifuge preparations. The slide was air-dried for $24 \mathrm{~h}$ before it was stained with May-Grunwald and Giemsa (Merck, Darmstadt, Germany). One hundred cells were counted and the percentage of alveolar macrophages (AM), PMN, other leukocytes and erythrocytes was calculated.

\section{Protein assay in BALF}

Total protein was quantified in the supernatant of BALF according to BRADFORD [17] in 96-well microtitre plates at $595 \mathrm{~nm}$, using bovine serum albumin (BSA) as a standard.

\section{Chemicals and solvents}

All chemicals were obtained from Sigma (Bornem, Belgium), unless mentioned otherwise. LPS from Salmonella enteritidis, lyophilized powder, was also obtained from Sigma, L6761, Lotnr. 55 F4013. Endotoxin-free Dulbecco's PBS, at pH 7.4 was used to dissolve LPS for IT aerosolization. Water was demineralized and further purified in a Milli-Q UF plus water purification system (Millipore, Etten-Leur, The Netherlands. Halothane was obtained from Albic BV, Maassluis, The Netherlands). Curosurf was made avail-able by Chiesi Farmaceutici, Parma, Italy. Each Curosurf vial $(3 \mathrm{~mL})$ contained $240 \mathrm{mg}$ porcine lung surfactant $\left(80 \mathrm{mg} \cdot \mathrm{mL}^{-1}\right)$ and $27 \mathrm{mg} \mathrm{NaCl}$ in distilled water Curosurf consisted of phospholipids for the major part (70\% of which is phosphatidylcholine) and about $1 \%$ SPB and SP-C.

\section{Statistics}

All data are presented as means \pm SEM. $f \mathrm{R}$ data were statistically analysed using the analysis of variance (ANOVA)/ analysis of covariance (ANCOVA) tests. For the ANCOVA analysis the following covariables were used: the average of the $f \mathrm{R}$ values of the LPS group between 4 and $9 \mathrm{~h}$ of the $10 \mathrm{~h}$ protocol and the $f \mathrm{R}$ values between 15 and $23 \mathrm{~h}$ for the $24 \mathrm{~h}$ protocol. Direct comparison between treatment groups and the LPS group was performed using the Student t-test. The LWW/BW values were analysed using ANOVA plus student t-test; significant differences between values for cell counts were tested by ANOVA (Poisson-distribution) plus Student t-test. Mean values were considered statistically significant if $\mathrm{p}<0.05$.

\section{Results}

In general, rats IT exposed to LPS (16 mg. $\left.\mathrm{kg}^{-1}\right)$, displayed symptoms of illness within $24 \mathrm{~h}$ after challenge. The clinical symptoms were: 1) raised fur; 2) loss of appetite; 3) loss of thirst; and 4) superficial breathing.

\section{Survival}

One week after LPS challenge, only 5 out of 14 animals $(35 \%)$ had survived when not treated with Curosurf (table 1). In contrast, Curosurf treatment at $10 \mathrm{~h}$ after LPS challenge resulted in $100 \%$ survival at both 62.5 and $125 \mathrm{mg}$. $\mathrm{kg}^{-1}$, which is highly significant $(\mathrm{p}<0.01)$; at a dose of 250 $\mathrm{mg} \cdot \mathrm{kg}^{-1}$ administered at $10 \mathrm{~h}$ after LPS instillation, one animal died between the second and third day after LPS

Table 1. - Survival of Curosurf-treated lipopolysaccharide (LPS)-challenged rats

\begin{tabular}{|c|c|c|c|c|c|c|}
\hline \multirow{2}{*}{ Treatment } & \multirow{2}{*}{$\begin{array}{c}\text { Curosurf dose } \\
\mathrm{mg} \cdot \mathrm{kg}^{-1}\end{array}$} & \multicolumn{5}{|c|}{ Survivors.group ${ }^{-1} \mathrm{n}$} \\
\hline & & $<24 \mathrm{~h}$ & $<48 \mathrm{~h}$ & $<72 \mathrm{~h}$ & $<1$ week & $>4$ weeks \\
\hline LPS $16 \mathrm{mg} \cdot \mathrm{kg}^{-1}$ & & $14 / 14$ & $10 / 14$ & $6 / 14$ & $5 / 14$ & $5 / 14$ \\
\hline \multirow[t]{3}{*}{ LPS + Curosurf $10 \mathrm{~h}$} & 62.5 & $6 / 6$ & $6 / 6$ & $6 / 6$ & $6 / 6$ & $6 / 6$ \\
\hline & 125 & $9 / 9$ & $9 / 9$ & $9 / 9$ & $9 / 9$ & 9/9 \\
\hline & 250 & $6 / 6$ & $6 / 6$ & $5 / 6$ & $5 / 6$ & $5 / 6$ \\
\hline LPS + Curosurf $24 \mathrm{~h}$ & 125 & $6 / 6$ & $6 / 6$ & $5 / 6$ & $5 / 6$ & $5 / 6$ \\
\hline
\end{tabular}




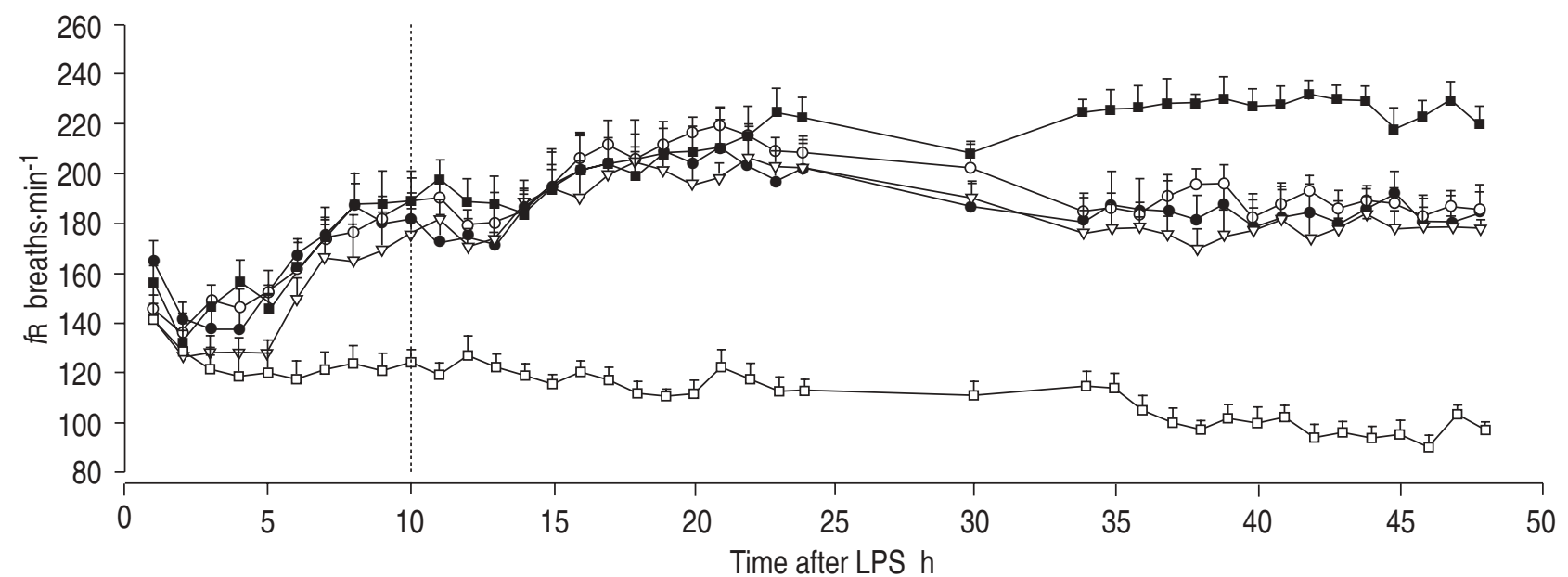

Fig. 1. - Respiratory frequency $(f \mathrm{R})$ of rats after intratracheal aerosolization of lipopolysaccharide $\left(\mathrm{LPS} ; \mathbf{\mathbf { m }}: 16 \mathrm{mg} \cdot \mathrm{kg}^{-1}\right)$ at $t=0$ and subsequent treatment with different doses of Curosurf $\left(\nabla: 62.5 \mathrm{mg} \cdot \mathrm{kg}^{-1} ; \mathrm{O}: 125 \mathrm{mg} \cdot \mathrm{kg}^{-1} ; \bullet: 250 \mathrm{mg} \cdot \mathrm{kg}^{-1}\right)$ at $10 \mathrm{~h}$ following LPS. Control animals only received phosphate-buffered saline $(\square)$ intratracheally instead of LPS. All values are means \pm sEM. Curosurf treatment, dose independently, started to result in a significant $(\mathrm{p}<0.01)$ improvement of $f \mathrm{R}$ at $34 \mathrm{~h}$, i.e. $14 \mathrm{~h}$ after intratracheal surfactant instillation, compared with $f \mathrm{R}$ values in the LPS group at the same time point.

challenge. One out of 6 animals died when $125 \mathrm{mg} \cdot \mathrm{kg}^{-1}$ Curosurf was administered $24 \mathrm{~h}$ after LPS instillation.

\section{Respiratory frequency}

Almost immediately after LPS challenge the $f \mathrm{R}$ started to increase (fig. 1). The data show that $f \mathrm{R}$ increased even after Curosurf treatment in all experimental groups until $25 \mathrm{~h}$ after LPS. Between 25 and $35 \mathrm{~h}$ after LPS challenge, $f \mathrm{R}$ significantly $(\mathrm{p}<0.01)$ decreased and remained stable until the end of the experiment. This $f R$ level, at which survival was possible, corresponded to that at $t=10 \mathrm{~h}$ after LPS, i.e. the moment at which Curosurf was administered. Following Curosurf treatment (at both doses) at $24 \mathrm{~h}$ after LPS administration, the $f \mathrm{R}$ value started to decrease at 10 $\mathrm{h}$ after its administration (fig. 2). In this experiment the decrease in $f \mathrm{R}$ became statistically significant $(\mathrm{p}<0.05)$ only at the lower dose (125 mg.kg-1) of Curosurf (fig. 2).

\section{Lung wet weight}

Challenge with LPS resulted in an enormous increase in LWW compared with that measured in animals exposed to PBS only (fig. 3). Independent of the dose and time of administration, Curosurf treatment resulted in a significant $(p<0.05)$ decrease of LWW, except for the value corresponding with the dose of $250 \mathrm{mg} \cdot \mathrm{kg}^{-1}$ at $10 \mathrm{~h}$ after LPS administration.

\section{Total protein in $B A L F$}

Total protein in BALF of LPS-challenged animals had increased about 10-fold at $48 \mathrm{~h}$ following LPS-challenge as compared with the PBS group (fig. 4). Irrespective of both the dose of Curosurf and the time point of administration (10 or $24 \mathrm{~h}$ after LPS), total protein had significantly decreased in all groups.

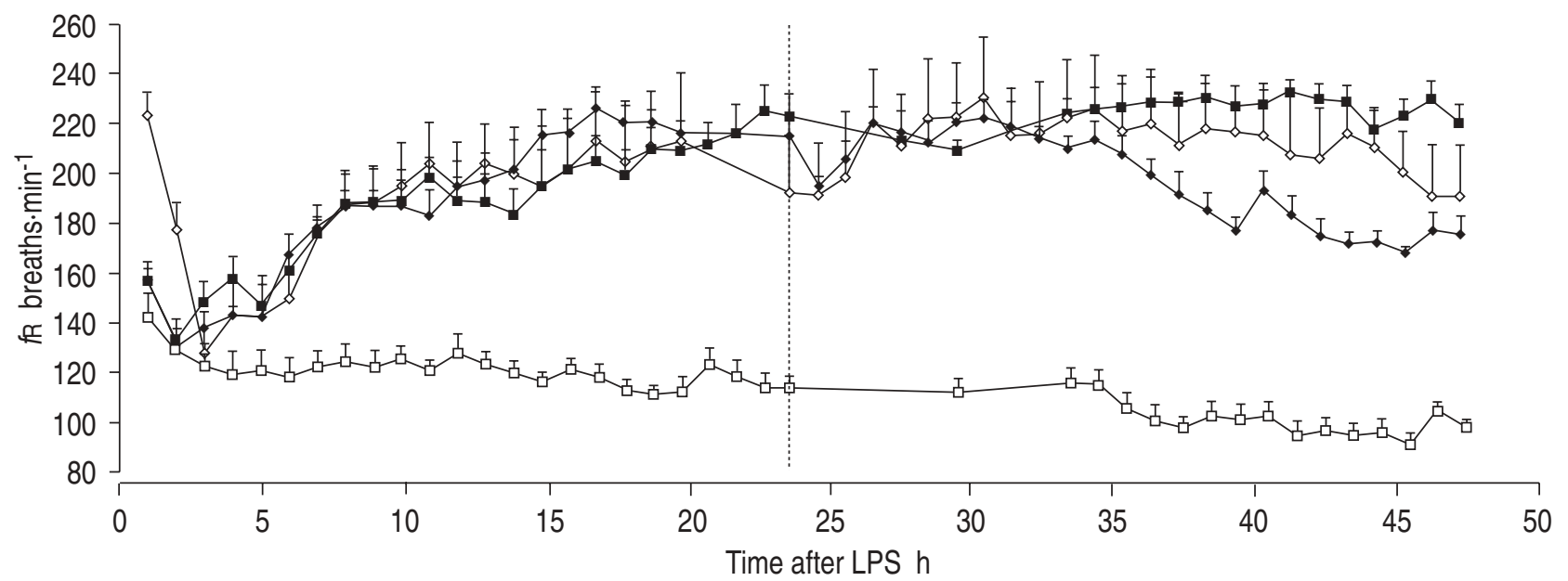

Fig. 2. - Respiratory frequency $(f \mathrm{R})$ of rats after intratracheal aerosolization of lipopolysaccharide $(\mathrm{LPS} ; \mathbf{m}: 16 \mathrm{mg} \cdot \mathrm{kg}-1)$ at $t=0$ and subsequent treatment with different doses of Curosurf $\left(\diamond: 125 \mathrm{mg} \cdot \mathrm{kg}^{-1} ; \diamond: 250 \mathrm{mg} \cdot \mathrm{kg}^{-1}\right)$ at $24 \mathrm{~h}$ following LPS. Control animals only received phosphate-buffered saline $(\square)$ intratracheally instead of LPS. All values are means \pm SEM. Curosurf treatment at a dose of $125 \mathrm{mg} \cdot \mathrm{kg}^{-1} \mathrm{started}$ to result in a significant (p<0.05) improvement of $f \mathrm{R}$ at $36 \mathrm{~h}$, i.e. $12 \mathrm{~h}$ after intratracheal surfactant instillation. Treatment with $250 \mathrm{mg} \cdot \mathrm{kg}^{-1}$ resulted in a significant $f \mathrm{R}$ improvement only at $47 \mathrm{~h}(\mathrm{p}<0.05)$. 


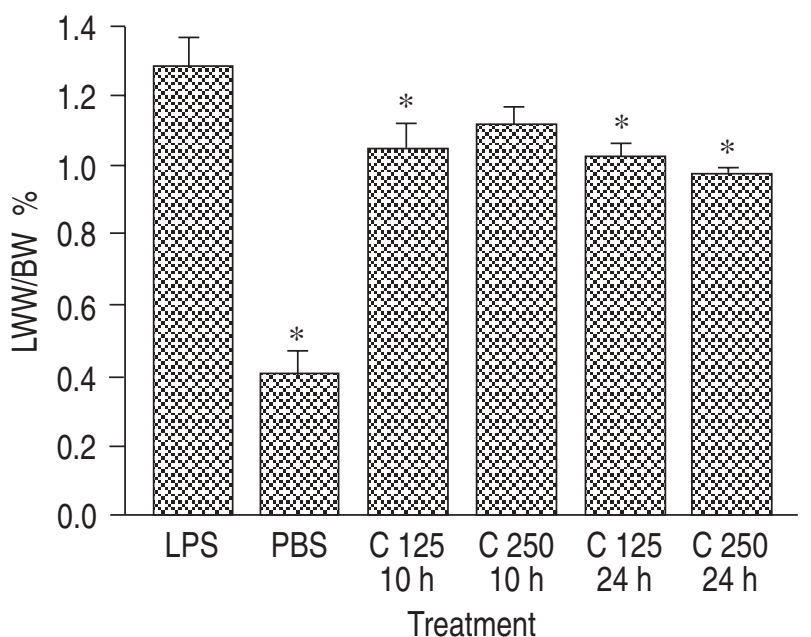

Fig. 3. - Lung wet weight (LWW) (\% LWW/body weight (BW)) determined in rats $(\mathrm{n}=6)$ at $48 \mathrm{~h}$ after lipopolysaccharide (LPS; $16 \mathrm{mg} \cdot \mathrm{kg}^{-1}$; $\mathrm{n}=6)$ or phosphate-buffered saline (PBS) administration $(\mathrm{n}=6)$. Animals receiving LPS were treated with Curosurf $\left(\mathrm{C} 125=125 \mathrm{mg} \cdot \mathrm{kg}^{-1} ; \mathrm{C} 250=\right.$ $\left.250 \mathrm{mg} \cdot \mathrm{kg}^{-1}\right)$ at either $10 \mathrm{~h}(\mathrm{n}=9$ and $\mathrm{n}=6$, respectively) or $24 \mathrm{~h}(\mathrm{n}=6$ and $\mathrm{n}=6$, respectively) following LPS. All values are means \pm SEM. $*: \mathrm{p}<0.05$ compared with the LPS group without Curosurf.

\section{Cell differentiation in $B A L F$}

LPS challenge led to increased numbers of AMs, PMNs and erythrocytes in BALF compared with that in PBS exposed control animals (fig. 5). Independent of the dose and time of administration, Curosurf treatment resulted in significantly decreased numbers of PMNs and erythrocytes.

\section{Discussion}

The main result of the present investigation was that Curosurf administered at 10 or $24 \mathrm{~h}$ after LPS challenge, decreased mortality, decreased $f \mathrm{R}$, decreased pulmonary

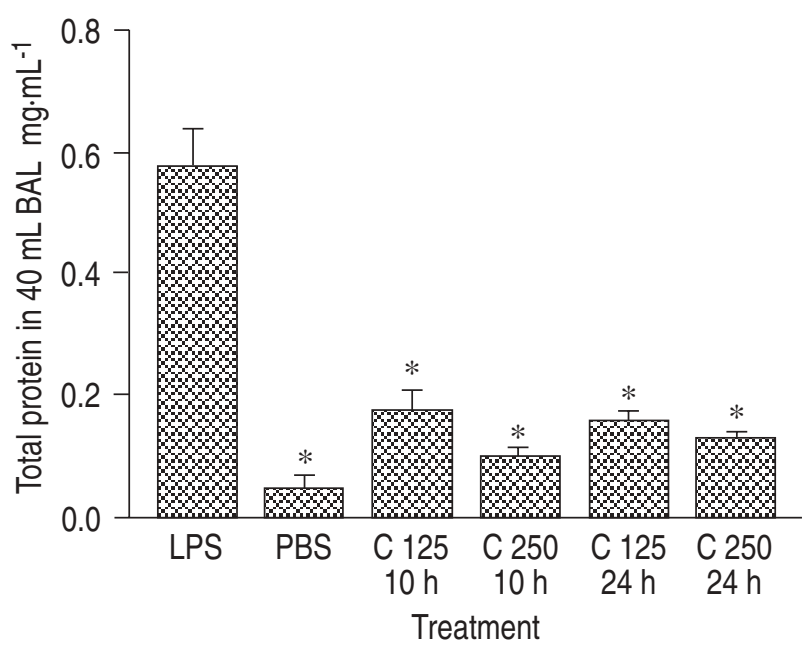

Fig. 4. - Total protein in bronchoalveolar lavage (BAL) fluid $48 \mathrm{~h}$ following administration of lipopolysaccharide (LPS; $16 \mathrm{mg} \cdot \mathrm{kg}^{-1}$ ) or phosphate-buffered saline (PBS) and treatment with different doses of Curosurf $\left(\mathrm{C} 125=125 \mathrm{mg} \cdot \mathrm{kg}^{-1} ; \mathrm{C} 250=250 \mathrm{mg} \cdot \mathrm{kg}^{-1}\right)$ at 10 or $24 \mathrm{~h}$ after LPS. The results are presented as mean \pm SEM with $n=6$. *: $\mathrm{p}<0.05 \mathrm{com}$ pared with LPS-challenge.

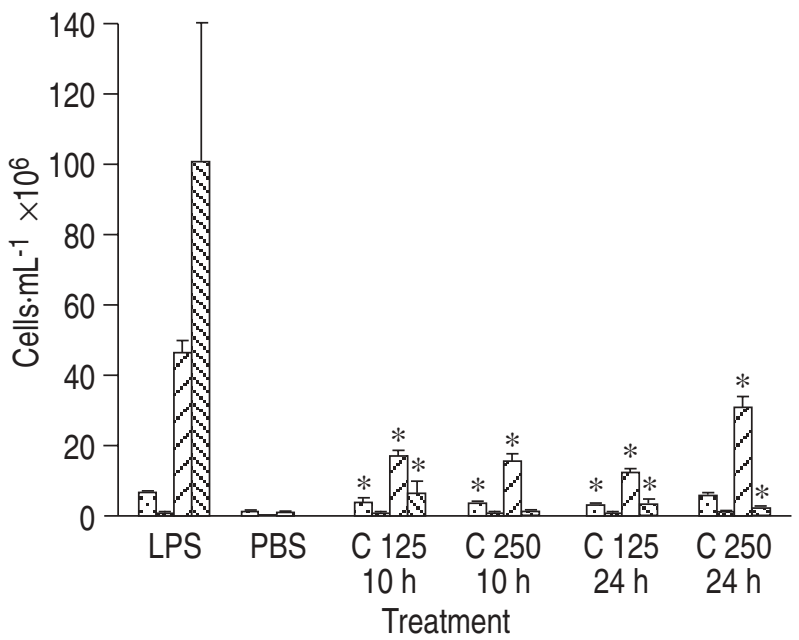

Fig. 5. - Counts of alveolar macrophages $(\because)$, polymorphonuclear cells (ख), lymphocytes ( $\square$ ) and erythrocytes $(\square)$ in bronchoalveolar lavage fluid obtained $48 \mathrm{~h}$ after lipopolysaccharide (LPS) $\left(16 ; \mathrm{mg} \cdot \mathrm{kg}^{-1}\right)$ challenge or phosphate-buffered saline (PBS) administration and treatment with Curosurf (C: same animals as in fig. 3). All values are means \pm SEM. $*:$ p $<0.05$ compared with the LPS group without Curosurf treatment.

oedema and decreased the extent of pulmonary inflammation in nonventilated, nonoxygenated ARDS-rats.

However, our results cannot easily be compared with those obtained in other animal models of ARDS testing other surfactant preparations. In the past several animal models have been proposed to study ARDS [10, 18]. Most of these models differ from human ARDS and from our model. In particular these models do not present the clinical development of ARDS (see [16]). The fact that in most ARDS patients Gram-negative sepsis is present, justifies in our view the use of LPS to induce ARDS. Using repetitive lung lavage, pulmonary virus infections or hydrochloric acid instillation to disturb the surfactant system, may induce a different form of lung injury, albeit that the ultimate lung injury obtained, often seems to be similar to that seen in ARDS patients. Apart from that, as far as surfactants were tested in these models, such treatments resulted in most cases in a (temporary) improvement of gas exchange. Moreover, many of these experiments were carried out under artificial respiration of anaesthetized animals and delivery of $100 \% \mathrm{O}_{2}$ whereas in the model used here the real physiological status of the respiratory system is measured in conscious "ARDS-animals".

A model which is comparable to ours is that used by KoваYASH et al. [19]. Using rats with an ARDS-type of injury induced by injection of endotoxin from Escherichia coli into the airway, they found that porcine surfactant replacement (by bolus: $100 \mathrm{mg} \cdot \mathrm{kg}^{-1}$ ) largely reversed this type of respiratory failure, provided the procedure was performed within $6 \mathrm{~h}$ after the endotoxin administration. They concluded that the surfactant replacement was effective only at the early stage (exudative phase), but has little effect on the late stage (proliferative phase) of the disease. They referred in this connection to the proliferative changes and the destruction of alveoli that are frequently observed in the lungs of patients who died of ARDS. However, these authors did not mention whether the rat ARDS lungs showed similar irreversible alterations already $6 \mathrm{~h}$ after LPS challenge. Neither did they mention 
how long their patients suffered from ARDS before they died. In contrast, in our model Curosurf was still effective when administered at $10 \mathrm{~h}$ and even at $24 \mathrm{~h}$ after LPS instillation, suggesting that irreversible alterations in the lung tissue were not yet present. Nevertheless, it would be relevant to assure a time limit or a stage of ARDS at which surfactant replacement is still effective and whether early replacement prevents irreversible destruction. Such physiological study should be accompanied by histological examinations.

Curosurf seemed to be more effective at improving $f \mathrm{R}$ in ARDS animals when given $10 \mathrm{~h}$ after LPS than at $24 \mathrm{~h}$. However, as the time span between Curosurf administration and the end of the experiment ( $48 \mathrm{~h}$ after LPS instillation) was shorter (fig. 2) than that in the first experiment (fig. 1), it remains to be established whether Curosurf is more effective when given $10 \mathrm{~h}$ after LPS.

The present study attempted to test single dose levels capable of establishing a dose-response relationship for the parameters measured. The results, however, did not demonstrate clear dose-response curves. On the basis of the preliminary data obtained we propose to extend the dose range for Curosurf towards lower dose levels (see below) in both protocols, paying attention initially to survival.

$f \mathrm{R}$ did not start to improve until $10-15 \mathrm{~h}$ following Curosurf treatment (fig. 1). This seems to be in contrast with our previous findings and data by others demonstrating that the gas exchange improved immediately, but mostly temporarily, following surfactant replacement in animals under artificial respiration and delivery of $100 \%$ $\mathrm{O}_{2}$. This temporary effect may be less relevant than the present ultimate improvement of respiration, since ARDS patients are usually oxygenated until they are able to breath spontaneously. A temporary improvement in gas exchange does not imply repair of lung injury induced by LPS. By binding harmful serum proteins, LPS and proteolytic enzymes, Curosurf may be able to limit the degree of tissue damage so that the repair process can take place more successfully. This neutralizing activity of Curosurf should also be investigated further.

Since only single doses of Curosurf were administered in the present experiments, the question remains whether multiple small doses could be more effective. Since one imagines that ARDS patients will have to be treated repeatedly with surfactant, the multiple dose administration should also be investigated. In the clinical trial with Survanta, mentioned in the Introduction, four or eight repetitive doses $\left(100 \mathrm{mg} \cdot \mathrm{kg}^{-1}\right)$ of Survanta were given to the ARDS patients in order to improve gas exchange and mortality. Insight in turnover rates of replaced surfactant might help to establish an optimal protocol for repeated administration. J0BE et al. [20] investigated the clearance of the major surfactant components (SP-A, SP-B and saturated phosphatidylcholine (Sat-PC)) from healthy adult rabbit lungs. The clearance curves for SP-A and SP-B were very similar with half-life values of 6-7 h; the half-life of Sat-PC was 11-12 h. It would be more relevant, however, to investigate the changes in the amounts of surfactant components in BALF from ARDS-animals. The outcome could perhaps be used to adapt the amount and composition of exogenous surfactant, assuming that replacement of too much surfactant or surfactant in the wrong composition might be harmful.

In this connection two interesting findings were obtained in a previous study using our model of ARDS [16]. Firstly, we found that at about $10 \mathrm{~h}$ after LPS challenge the amount of SP-A was largely increased in BALF; whereas this coincided with a dip in the amount of pulmonary oedema. This may reflect an important property of newly secreted SP-A: the protection of functional surfactant against inactivation by proteolytic enzymes. Such an effect of SP-A has been reported both in vitro [21] and in vivo [22]. Another important function of this enhanced amount of SP-A in BALF of ARDS animals might be that this effect may be related to the SP-A-dependent formation of tubular myelin and the role of SP-A in surface film formation [23]. Support for this hypothesis was reported by MaLloy et al. [24], showing that SP-A levels were enhanced, whereas the small surfactant aggregate (SA) to large surfactant aggregate (LA) ratio was lower than in control animals. LA are functionally superior to SA. This could also explain why Curosurf was effective at $10 \mathrm{~h}$ after LPS, in spite of its own lack of SP-A. It would also be relevant in this connection to investigate the amounts of SP-A and SP-D in BALF of ARDS animals before and after the administration of Curosurf, i.e. the components which are not present in Curosurf but which may reflect the amount of new surfactant produced by the type II cells. Secondly, VAN HeLDen et al. [16] also demonstrated a maximal concentration of TNF- $\alpha$ in BALF at $5 \mathrm{~h}$ after LPS administration. At $10 \mathrm{~h}$ after LPS the amount of TNF- $\alpha$ was very low, whereas SP-A had reached a maximal concentration. This might reflect that TNF- $\alpha$ triggers the release of SP-A and that SP-A subsequently decreases the TNF- $\alpha$ production by LPS-activated macrophages, suggesting that this collectin may play a role in the immediate inflammatory response. It has been reported that TNF- $\alpha$ affects the SP-A production $[25,26]$ and vice versa [26, 27]. An ultimate decrease in SP-A in BALF between 15 and $24 \mathrm{~h}$ after LPS instillation coincided with a large increase in oedema. These findings suggest that addition of SP-A to exogenous surfactant or administration of SP-A containing surfactant could enhance the efficacy of the treatment.

Surfactant preparations like Curosurf containing the hydrophobic surfactant proteins SP-B and SP-C adsorb very rapidly to an air-liquid interface and, when administered endotracheally in sufficient amounts, they effectively compensate for surfactant deficiency in babies with respiratory distress syndrome. The efficiency of surfactant therapy in ARDS may also depend on the amounts of SP$\mathrm{B}$ and SP-C.

In conclusion, Curosurf treatment led to an improved physiological status of the lung, a decreased mortality, a decreased pulmonary oedema and a decreased inflammatory reaction in an animal model which mimics the clinical development of acute respiratory distress syndrome very closely. As the decreased mortality was observed in spontaneously breathing nonoxygenated animals, the results cannot be extrapolated to human artificially ventilated acute respiratory distress syndrome patients, to expect a decrease in mortality. Therefore, the results suggest that Curosurf may be an important therapeutic measure for early-stage acute respiratory distress syndrome. 


\section{References}

1. Ashbaugh DG, Bigelow DB, Petty TL, Levine BE. Acute respiratory distress in adults. Lancet 1967; 2: 319-323.

2. Milberg JA, Davis DR, Steinberg KP, Hudson LD. Improved survival of patients with acute respiratory distress syndrome (ARDS): 1983-1993. JAMA 1995; 273 (4): 306-309.

3. Anzueto A, Baughman RP, Guntupalli KK, et al. Aerosolized surfactant in adults with sepsis-induced acute respiratory distress syndrome. Exosurf Acute Respiratory Distress Syndrome Sepsis Study Group. N Engl J Med 1996; 334: 1417-1421.

4. Lachmann B, Danzmann E. Acute respiratory distress syndrome. In: Robertson B, Van Golden LMG, Batenburg JJ, eds. Pulmonary Surfactant. Amsterdam, Elsevier, 1984; pp. $505-548$.

5. Gregory TJ, Longmore WJ, Moxley MA. Surfactant chemical composition and biophysical activity in acute respiratory distress syndrome. J Clin Invest 1991; 88: 1976-1981.

6. Lachmann B. The role of pulmonary surfactant in the pathogenesis of ARDS. In: Vincent JL, ed. Update in Intensive Care and Emergency Medicine. Berlin, Heidelberg, New York, Springer, 1987; pp. 123-134.

7. Richman PS, Spragg RG, Robertson B, Merritt TA, Curstedt $\mathrm{T}$. The adult respiratory distress syndrome: first trials with surfactant replacement. Eur Respir J 1989; 2: 109-111.

8. Nosaka S, Sakai T, Yonekura M, Yoshikawa K. Surfactant for adults with respiratory failure. Lancet 1990; 1: 947948.

9. Gommers D, Lachmann B. Surfactant therapy: does it have a role in adults? Clin Int Care 1993; 4: 284-295.

10. Lewis JF, Jobe AH. Surfactant and the adult respiratory distress syndrome. Am Rev Respir Dis 1993; 147: 218-233.

11. Lachmann B, Van Daal GJ. Adult respiratory distress syndrome: animal models. In: Robertson B, Van Golden LMG, Batenburg JJ, eds. Pulmonary Surfactant. Amsterdam, Elsevier, 1992; pp. 635-663.

12. Spragg RG. Clinical results after natural and artificial exogenous surfactant therapy. Appl Cardiopulm Pathophysiol 1995; 5: 116.

13. Gadek JE, Gregory TJ, Hyers TM, Longmore WJ, Spragg R, Steinberg KP. Patterns of improvement of gas exchange during treatment of patients with the adult respiratory distress syndrome with a bovine derived surfactant. Appl Cardiopulm Pathophysiol 1995; 5: 36.

14. Gregory TJ, Steinberg KP, Spragg R, et al. Bovine surfactant therapy for patients with acute respiratory distress syndrome. Am J Respir Crit Care Med 1997; 155 (4): 1309-1315.

15. Walmrath D, Gunther A, Ghofrani HA, et al. Bronchoscopic surfactant administration in patients with severe adult respiratory distress syndrome and sepsis. Am J Respir Crit Care Med 1996; 154: 57-62.

16. Van Helden HPM, Kuijpers WC, Steenvoorden D, et al. Intratracheal aerosolization of endotoxin (LPS) in the rat: a comprehensive animal model to study Adult (Acute) Respiratory Distress Syndrome (ARDS). Exp Lung Research 1997; 23: 297-315.

17. Bradford MM. A rapid and sensitive method for quantification of microgram quantities of protein utilizing the principle of protein dye binding. Anal Biochem 1976; 72: 248-254.

18. Lachmann B, Gommers D, Eijking EP. Exogenous surfactant therapy in adults. Atemw Lungenkrkh 1993; 12: S581-S591.

19. Kobayashi T, Tashiro K, Li WZ, Matsumoto Y, Yamada K. Experimental experiences with exogenous surfactant in animals with adult respiratory distress syndrome (ARDS). Appl Cardiopulm Pathophysiol 1993; 5: 71-72.

20. Jobe AH, Ueda T, Henry M, Ikegami M. Clearance of the major surfactant components from rabbit lungs. Appl Cardiopulm Pathophysiol 1995; 5: 65-66.

21. Cockshutt AM, Weitz J, Possmayer F. Pulmonary surfactant-associated protein A enhances the surface activity of lipid extract surfactant and reverses inhibition by blood proteins in vitro. Biochemistry 1990; 29: 8424-8429.

22. Yukitake K, Brown CL, Schlueter MA, Clements JA, Hawgood S. Surfactant apoprotein A modifies the inhibitory effect of plasma proteins on surfactant activity in vivo. Pediatr Res 1995; 37: 21-25.

23. Putman E, Creuwels LAJM, Van Golde LMG, Haagsman HP. Surface properties, morphology, and protein composition of pulmonary surfactant subtypes. Biochem J 1996; 320: 599-605.

24. Malloy J, McCaig L, Veldhuizen R, et al. Alterations of the endogenous surfactant system in septic adult rats. Am J Respir Crit Care Med 1997; 156: 617-623.

25. Clements JA. Function of the alveolar lining. Am Rev Respir Dis 1977; 115: 67-71.

26. McIntosh JC, Wright JR. SP-A decreases TNF $\alpha$ production by LPS-activated macrophages. Appl Cardiopulm Pathophysiol 1995; 5: 80-81.

27. Whitsett JA, Clark JC, Wisp JR, Pryhuber GS. Effects of TNF- $\alpha$ and phorbol ester on human surfactant protein and MnSOD gene transcription in vitro. Am J Physiol 1992; 262: L688-L693. 